\title{
Infection and Immunity
}

\section{Complement C3 Plays an Essential Role in the Control of Opportunistic Fungal Infections}

S. Vicky Tsoni, Ann M. Kerrigan, Mohlopheni J. Marakalala, Naren Srinivasan, Maureen Duffield, Philip R. Taylor, Marina Botto, Chad Steele and Gordon D. Brown

Infect. Immun. 2009, 77(9):3679. DOI: 10.1128/IAI.00233-09. Published Ahead of Print 6 July 2009.

Updated information and services can be found at:

http://iai.asm.org/content/77/9/3679

These include:

REFERENCES

This article cites 31 articles, 15 of which can be accessed free at: http://iai.asm.org/content/77/9/3679\#ref-list-1

CONTENT ALERTS

Receive: RSS Feeds, eTOCs, free email alerts (when new articles cite this article), more» 


\title{
Complement C3 Plays an Essential Role in the Control of Opportunistic Fungal Infections ${ }^{\nabla}$
}

\author{
S. Vicky Tsoni, ${ }^{1}$ Ann M. Kerrigan, ${ }^{1}$ Mohlopheni J. Marakalala,${ }^{1}$ Naren Srinivasan, ${ }^{1}$ Maureen Duffield, ${ }^{2}$ \\ Philip R. Taylor, ${ }^{3}$ Marina Botto, ${ }^{4}$ Chad Steele, ${ }^{5}$ and Gordon D. Brown ${ }^{1,6 *}$ \\ Institute of Infectious Disease and Molecular Medicine, Division of Immunology, ${ }^{1}$ and Department of Anatomical Pathology, ${ }^{2}$ \\ CLS, University of Cape Town, Cape Town 7925, South Africa; Department of Medical Biochemistry and Immunology, \\ Cardiff University School of Medicine, Cardiff CF14 4XN, United Kingdom ${ }^{3}$; Imperial College, Faculty of \\ Medicine, Hammersmith Campus, London W12 0NN, United Kingdom ${ }^{4}$; Department of Medicine, \\ University of Alabama at Birmingham, Birmingham, Alabama ${ }^{5}$; and Aberdeen Fungal Group, Section of \\ Immunology and Infection, Division of Applied Medicine, Institute of Medical Sciences, Foresterhill, \\ University of Aberdeen, Aberdeen AB25 2ZD, United Kingdom ${ }^{6}$
}

Received 27 February 2009/Returned for modification 12 April 2009/Accepted 23 May 2009

\begin{abstract}
The innate recognition of fungal pathogens is a crucial first step in the induction of protective antifungal immunity. Complement is thought to be one key component in this process, facilitating fungal recognition and inducing early inflammation. However, the roles of the individual complement components have not been examined extensively. Here we have used mice lacking $\mathrm{C} 3$ to examine its role in immunity to opportunistic fungal pathogens and show that this complement component is essential for resistance to infections with Candida albicans and Candida glabrata. We demonstrate that the absence of $\mathrm{C} 3$ impairs fungal clearance but does not affect inflammatory responses. We also show that the presence of $\mathrm{C} 3$ contributes to mortality in mice challenged with very high doses of Saccharomyces cerevisiae, although these effects were found to be mouse strain dependent.
\end{abstract}

Over the last few decades, modern medical practice and acquired immunodeficiencies have contributed to a substantial increase in the incidence of infections with normally commensal or nonpathogenic fungi (22), prompting a renewed interest in expanding our understanding of the mechanisms underlying protective host immunity. Identification and characterization of the receptors involved in the innate recognition of these organisms are of particular importance, as these "pattern recognition receptors" (14) not only are responsible for mediating the recognition and uptake of fungi by phagocytes but also initiate and direct the resultant immune response (17). While numerous nonopsonic pattern recognition receptors for fungi have been well characterized, including several members of the C-type lectin and Toll-like receptor families (for recent reviews, see references 20,21 , and 32 ), less is known about the opsonic mechanisms of fungal recognition, such as those mediated by complement, despite the essential role of these systems in antifungal immunity (24).

The complement system consists of more than 30 serum and cellular surface proteins and is activated through three main routes: the classical, alternative, and lectin pathways. Triggering of these three pathways initiates enzymatic cascades which converge on the third complement component, $\mathrm{C} 3$, whose activation leads ultimately to microbial opsonization, the release of chemotactic factors, including $\mathrm{C} 3 \mathrm{a}$ and $\mathrm{C} 5 \mathrm{a}$, and the gener-

\footnotetext{
* Corresponding author. Mailing address: Section of Immunity and Infection, Room 4.20, Institute of medical sciences, University of Aberdeen, Ashgrove Road West, Aberdeen, United Kingdom AB25 2ZD. Phone: 44-1224-555796. Fax: 44-1224-555844. E-mail: gordon .brown@abdn.ac.uk.

${ }^{\nabla}$ Published ahead of print on 6 July 2009.
}

ation of a membrane attack complex (MAC) (18). Activation of the classical pathway occurs primarily following the binding of C1q to antibody-antigen complexes, and although involved in the adaptive arm of the immune system, this pathway is also triggered by natural antibodies, thereby contributing to the innate recognition of fungi (16). Initiation of the alternative pathway occurs through the spontaneous activation of $\mathrm{C} 3$ on microbial surfaces, and the lectin pathway is initiated by the binding of the mannose-binding lectin to carbohydrates on microbial surfaces (24).

All three of these pathways are induced by opportunistic fungal pathogens, including Candida albicans (13, 15, 24), although the alternative pathway may be the most critical $(7,15)$. The protective role of complement in immunity to these pathogens has largely been determined in mice treated with cobra venom factor (CVF), which depletes serum complement by forming a potent $\mathrm{C} 3$ convertase, or in C5-deficient mouse strains, such as A/J or DBA2, where fungal opsonization remains intact but the animals lack the ability to generate C5a or the MAC $(6,7,9,10,19)$. Why C5-deficient mice are susceptible is still unclear, but is likely to be due to aberrant inflammatory responses, as the MAC has little effect on the viability of fungal pathogens $(15,19)$. Although the roles of each of the pathways of complement activation have been relatively poorly examined, recent studies have started to address this issue, looking at the role of factor B, C2, C1q and mannose-binding lectin in the control of systemic candidiasis (11).

C3 is a central component in all of the complement pathways, as described above, but it has not been studied in isolation with respect to fungal infection. Studying the role of this complement component in isolation is particularly relevant, given the alternative route of $\mathrm{C} 5$ activation by thrombin, which 


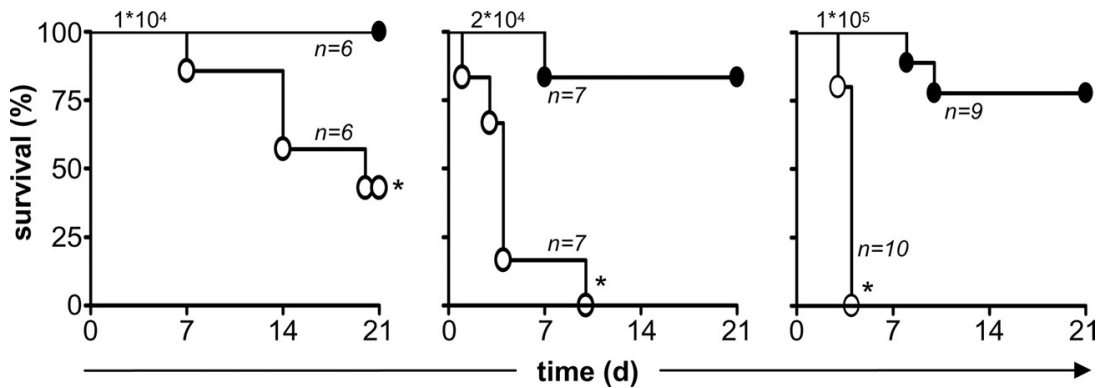

FIG. 1. C3 deficiency increases susceptibility to infection with C. albicans. C57BL/6 wild-type $(\bullet)$ and C3-deficient $(\bigcirc)$ mice were infected with a low $\left(1 \times 10^{4} \mathrm{CFU}\right)$, intermediate $\left(2 \times 10^{4} \mathrm{CFU}\right)$, or high $\left(1 \times 10^{5} \mathrm{CFU}\right)$ dose of $C$. albicans i.v. and were monitored for survival over 21 days, as described in Materials and Methods. The numbers of mice infected in each experiment are indicated in the figure and are representative of at least two independent experiments $\left(1 \times 10^{4}\right.$ and $\left.2 \times 10^{4} \mathrm{CFU}\right)$ or a single experiment $\left(1 \times 10^{5} \mathrm{CFU}\right)$. *, $P<0.05$.

can substitute for C3-dependent C5 convertase activity (12, 30). Therefore, we undertook to specifically examine the role of $\mathrm{C} 3$ in the control of opportunistic fungal infections using C3-sufficient and C3-deficient mice.

\section{MATERIALS AND METHODS}

Mice. Seven- to 14-week-old female C57BL/6, C57BL/6 C3 ${ }^{-1-}$ (backcrossed for 10 generations) (29), $\mathrm{DBA} / 2$, and $\mathrm{BALB} / \mathrm{c}$ mice were obtained from the specific-pathogen-free facility of the University of Cape Town. All animal experimentation was repeated at least once, unless otherwise indicated, and conformed to institutional guidelines for animal care and welfare. All experiments utilized at least six mice per group.

Systemic fungal models. C. albicans SC5314 (27) in Sabouraud broth at $30^{\circ} \mathrm{C}$ or Candida glabrata (ATCC 2001) and Saccharomyces cerevisiae BY4741 (3), in yeast-peptone-dextrose broth at $37^{\circ} \mathrm{C}$ were cultured for $24 \mathrm{~h}$. Yeasts were washed twice in phosphate-buffered saline (PBS) and intravenously (i.v.) inoculated in $100 \mu \mathrm{l}$ into anesthetized animals, at the doses described in the text. Mice were sacrificed at various time points, as described, or when judged moribund, which included $20 \%$ loss of body weight. All remaining mice were sacrificed at 21 days, which was considered to be the end of the experiment

Peritoneal candidiasis. The in vivo peritoneal inflammatory response mode was performed essentially as described previously (27). In brief, mice were inoculated intraperitoneally (i.p.) with $C$. albicans (SC5314; $1 \times 10^{6}$ or $1 \times 10^{7}$ $\mathrm{CFU})$ and were sacrificed after $4 \mathrm{~h}$ or 4 days. The peritoneal inflammatory infiltrate was collected by lavage with $2 \mathrm{ml}$ ice-cold $5 \mathrm{mM}$ EDTA in PBS Cytokines and cellular populations in the inflammatory isolates were analyzed as described below.

To demonstrate the presence of complement in the peritoneal cavity, lavage fluid was harvested following the injection of $2 \mathrm{ml}$ of Hanks balanced salt solution (HBSS) into the peritoneum. This fluid was then used to opsonize $C$. albicans yeast for $30 \mathrm{~min}$ at $37^{\circ} \mathrm{C}$ with shaking. Freshly collected serum (used at $40 \%$ in HBSS) was used as a control. The yeast particles were then washed with HBSS, and the deposition of C3 was determined by flow cytometry, as described below.

Flow cytometery and antibodies. Fluorescence-activated cell sorting (FACS) was performed according to conventional protocols at $4^{\circ} \mathrm{C}$ in the presence of 2 $\mathrm{mM} \mathrm{NaN}_{3}$, as previously described (26). Surface expression of selected markers was detected using fluorescein isothiocyanate (FITC)-conjugated anti-C3, biotinconjugated anti-Gr-1, FITC-conjugated anti-7/4, FITC-conjugated anti-CD11b (clone 5C6) (23), anti-F4/80, and irrelevant rat immunoglobulin G2b biotin- and /FITC-unconjugated isotype controls (all produced in house). Phycoerythrinconjugated donkey anti-rat immunoglobulin G (Jackson) was used as a secondary antibody to detect unlabeled primary antibodies. Biotinylated antibodies were detected using streptavidin-allophycocyanin (BD, Pharmingen). Cells were fixed with $1 \%$ formaldehyde in PBS before analysis. All FACS analyses were performed using a BD Biosciences FACSCalibur and CellQuest software.

Cytokine and MPO analysis. Growth factor, chemokine, and cytokine concentrations were measured in kidney homogenates, serum, or peritoneal lavage fluids using the Bio-Plex protein array system (Bio-Rad) as directed by the manufacturer. Kidney homogenates were prepared by homogenizing the organs in PBS containing $0.05 \%$ Triton $\mathrm{X}-100$ and protease inhibitors (Complete EDTA-free protease inhibitor cocktail; Roche). Myeloperoxidase (MPO) activ- ity was determined by homogenizing isolated kidneys in hexadecyl trimethyl ammonium bromide buffer. The homogenate was sonicated for 20 pulses at an output of $9 \mathrm{~W}$ followed by centrifugation for $10 \mathrm{~min}$ at $10,000 \times g$ to remove any remaining fragments of tissue. $o$-Dianisidine was added to a sample of the homogenate, and the mixture was incubated at $35^{\circ} \mathrm{C}$ for $10 \mathrm{~min}$. The amount of MPO activity was determined by measuring the absorbance following the addition of $0.005 \% \mathrm{H}_{2} \mathrm{O}_{2}$ at $460 \mathrm{~nm}$.

Statistics. Student's $t$ test was used for analysis of two groups, with paired analysis when appropriate, while the Mann-Whitney test was used for the analysis of nonparametrically distributed data. Survival data were analyzed with the $\log$ rank test. Results were considered statistically significant with $P$ values of $<0.05$.

\section{RESULTS}

Mice deficient in $\mathrm{C} 3$ are susceptible to infection with $C$. albicans. To explore the role of C3 in the control of fungal infection, we systemically infected C3-sufficient and -deficient mice with a low $\left(1 \times 10^{4} \mathrm{CFU}\right)$, intermediate $\left(2 \times 10^{4} \mathrm{CFU}\right)$, or high $\left(1 \times 10^{5} \mathrm{CFU}\right)$ dose of $C$. albicans SC5314 and monitored survival of the animals over time (Fig. 1). In contrast to wild-type mice, which were fully resistant to infection with the low dose of $C$. albicans, more than $55 \%$ of the $\mathrm{C} 3^{-1-}$ mice died during the course of this experiment. All of the $\mathrm{C} 3^{-1-}$ mice rapidly succumbed to the infection with the higher inoculums of $C$. albicans, although these doses also induced some mortality in the wild-type animals.

To characterize the susceptibility of the C3-deficient mice in more detail, we examined animals at day 3 following systemic infection with a low dose $\left(1 \times 10^{4} \mathrm{CFU}\right)$ of $C$. albicans (Fig. 2). This early time point was chosen to allow immunological differences to be determined, prior to the mice succumbing to infection (Fig. 1). We first examined the kidney, which is the target organ for C. albicans in mice (1), and found significantly higher fungal burdens in $\mathrm{C}^{-/-}$animals $(28,150 \pm 7,657$ $\mathrm{CFU} / \mathrm{g})$ compared to the wild-type controls $(3,611 \pm 1,850$ CFU/g) (Fig. 2A). These higher fungal burdens correlated with significantly elevated levels of a variety of proinflammatory cytokines and chemokines (Fig. 2B), and we also observed significantly elevated levels of interleukin-1 $\alpha$ (IL- $1 \alpha)$, granulocyte colony-stimulating factore (G-CSF), Keratinocyte-derived chemokine $(\mathrm{KC})$, and IL-17 in the peripheral blood of the $\mathrm{C}^{-1-}$ mice, although no Candida was detectable in the blood at this time point (Fig. 2C) (data not shown). We also observed increased leukocyte accumulation (predominantly neutrophils and macrophages) in the kidneys of the $\mathrm{C}^{-1-}$ animals, which 
A

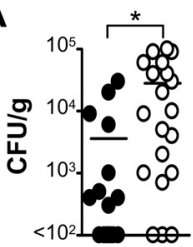

C

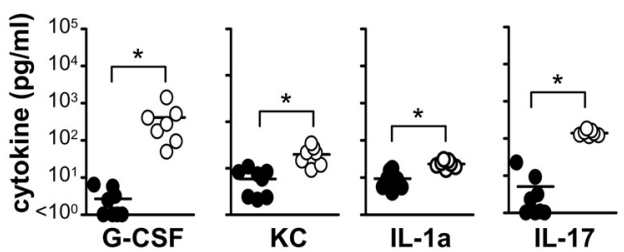

B

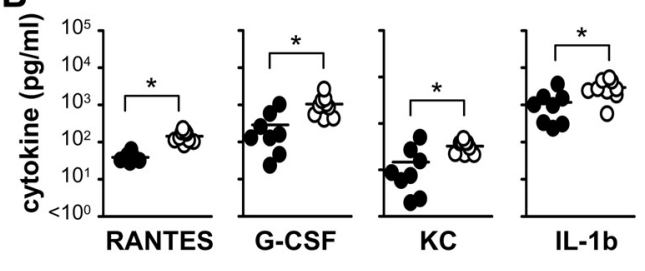

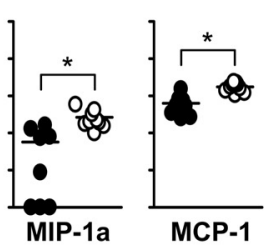
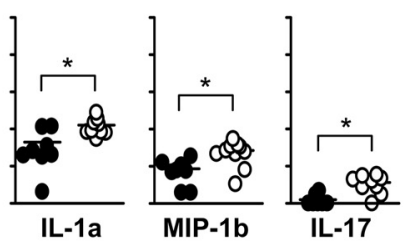

E

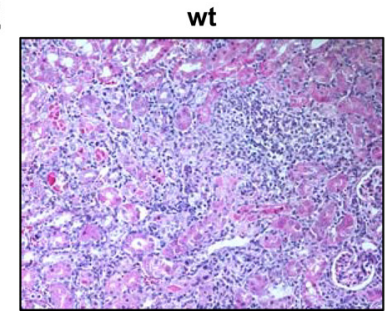

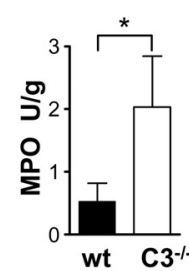

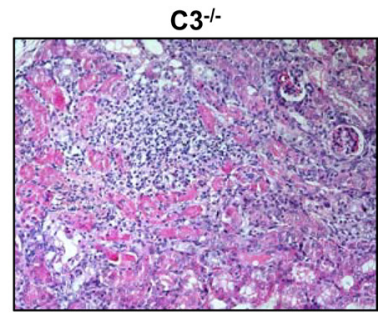

FIG. 2. C3 deficiency correlates with increased inflammation and fungal burdens. On day 3 following i.v. infection with a low dose $\left(1 \times 10^{4}\right.$ $\mathrm{CFU}$ ) of C. albicans, higher fungal burdens (A) and exacerbated inflammatory cytokines (B) were observed in the kidneys of C3-deficent mice ( $\bigcirc$ ) compared to wild-type (wt) animals $(\bullet)$. The values are as follows: RANTES, $145 \pm 16$ versus $39 \pm 4 \mathrm{pg} / \mathrm{ml}$; G-CSF, $1,054 \pm 228$ versus $290 \pm$ $120 \mathrm{pg} / \mathrm{ml} ; \mathrm{KC}, 326 \pm 32$ versus $147 \pm 57 \mathrm{pg} / \mathrm{ml}$; IL-1 $\beta$ (IL-1b), $2,936 \pm 492$ versus 1,184 $\pm 290 \mathrm{pg} / \mathrm{ml}$; macrophage inhibitory protein 1 $\alpha$ (MIP-1a), $265 \pm 51$ versus $57 \pm 23 \mathrm{pg} / \mathrm{ml}$; IL-1 $\alpha$ (IL-1a), $127 \pm 24$ versus $44 \pm 16 \mathrm{pg} / \mathrm{ml}$; macrophage inhibitory protein $1 \beta$ (MIP-1b), $27 \pm 5$ versus $9 \pm$ $2 \mathrm{pg} / \mathrm{ml}$; and IL-17, $3.6 \pm 0.6$ versus $1.3 \pm 0.2 \mathrm{pg} / \mathrm{ml}$. Higher levels of selected proinflammatory cytokines were also detected in the peripheral blood of these animals (C). The values are as follows: G-CSF, $414 \pm 176$ versus $2 \pm 1 \mathrm{pg} / \mathrm{ml} ; \mathrm{KC}, 199 \pm 34$ versus $59 \pm 12 \mathrm{pg} / \mathrm{ml}$; IL-1 $\alpha, 23 \pm 2$ versus $9 \pm 2 \mathrm{pg} / \mathrm{ml}$; and IL-17, $141 \pm 9$ versus $5 \pm 3 \mathrm{pg} / \mathrm{ml}$. Although there was a significant increase in polymorphonuclear leukocyte accumulation in the kidneys of the $\mathrm{C}^{-1-}$ animals, as quantified by histology (not shown) and measurement of MPO activity (D), there was no difference in the gross pathologies of these tissues, as determined by hematoxylin and eosin staining (E). $*, P<0.05$ ( $n>7$ animals per group per experiment). The data shown in panel A are pooled from two independent experiments. Bars indicate mean values of the data.

was quantified by measuring MPO activity (Fig. 2D). However there was no difference in the gross pathologies of kidneys from infected wild-type and $\mathrm{C}^{-/-}$mice at this time point (Fig. 2E). Overall, these results demonstrate that C3 is essentially required for resistance to infection with $C$. albicans.

The loss of $\mathrm{C} 3$ does not affect early inflammatory responses but delays fungal clearance. The susceptibility of the C3-deficient mice to systemic infection with $C$. albicans is likely to be due to defects in fungal clearance and/or defective inflammatory responses. We first explored the latter possibility and characterized inflammatory responses following peritoneal challenge with $C$. albicans, using a model we had previously used to characterize inflammatory defects in Dectin- $1^{-/}$mice (27). Although not truly representative of systemic infection, this model allows for the quantitation of inflammatory responses and was appropriate for this study as we could show that complement was present in the peritoneal cavity (Fig. 3A). For these experiments, we infected mice i.p. with $1 \times 10^{6} \mathrm{CFU}$ of $C$. albicans, and inflammatory responses were monitored at early ( $4 \mathrm{~h})$ and late (4 days) time points (Fig. 3B to E). By 4 h, there was no defect in the inflammatory response of the $\mathrm{C} 3$ deficient animals, both in terms of cellular recruitment (total cells, neutrophils, and monocytes) (Fig. 3B and C) as well as in the production of peritoneal cytokines (Fig. 3D). In fact, there were slightly higher levels of $\mathrm{KC}$, eotaxin, and IL-1 $\beta$ in the $\mathrm{C}^{-1-}$ mice, although this is unlikely to be biologically relevant. Similar findings were also obtained at $4 \mathrm{~h}$ following i.p. infection with a high dose $\left(1 \times 10^{7} \mathrm{CFU}\right)$ of $C$. albicans (Fig. $3 \mathrm{E})$. These data therefore suggest that early inflammatory responses are not significantly affected by C3 deficiency.

By day 4, following i.p. infection with a low dose of $C$. albicans, we did observe a slight, but significant, reduction in the total numbers of cells recruited to the peritoneal cavity in the $\mathrm{C}^{-1-}$ animals, although the relative percentage of the various cellular subpopulations, such as macrophages, remained unchanged (Fig. 4A and B) (data not shown). Furthermore, we did not detect differences in the level of any cytokine between wild-type and $\mathrm{C}^{-1-}$ animals (Fig. 4C). We were unable to explore the effect of $\mathrm{C} 3$ deficiency with higher fungal doses on day 4 , as the $\mathrm{C} 3^{-/-}$mice succumbed to infection by this time point (data not shown). These results therefore suggest that C3 deficiency does not significantly affect inflammatory responses to $C$. albicans.

We next examined fungal clearance following systemic infection in wild-type and C3-deficient mice. For these experiments, mice were infected i.v. with a low dose $\left(1 \times 10^{4} \mathrm{CFU}\right)$ of $C$. albicans and the clearance of this pathogen from various organs was monitored over time (24, 48, and 72 h) (Fig. 5). By $24 \mathrm{~h}$, delayed clearance was evident, with higher fungal burdens detected in the organs of most of the $\mathrm{C}^{-/-}$mice. In contrast, the organs of many of the wild-type animals had undetectable fungal loads, except for the spleen and kidney. By $48 \mathrm{~h}$, C. albicans could still be detected in all of the organs of some $\mathrm{C}^{-/-}$animals, although only the fungal burdens in the spleen and kidney were significantly different from those of the wild-type animals. By 72 h, although not significantly different, there was evidence of fungal outgrowth in the organs of $\mathrm{C} 3^{-/-}$ animals, including the lung and brain, whereas the wild-type animals had largely contained the infection by this time point and appeared to have started clearing the fungus from their kidneys and spleen. Thus, these data suggest that the enhanced susceptibility of C3-deficient animals to C. albicans stems from their inability to clear the pathogen. 
A
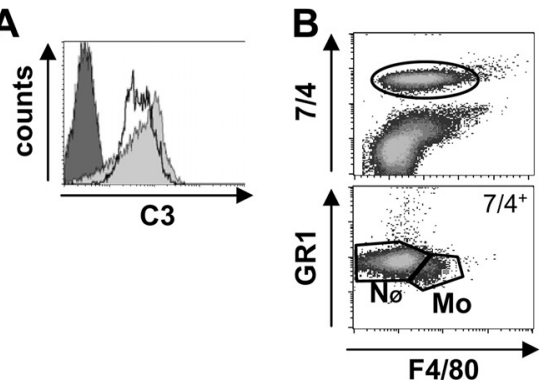

C

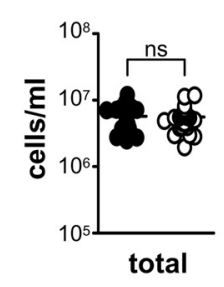

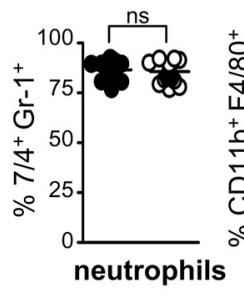

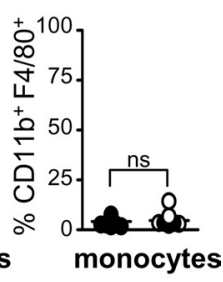

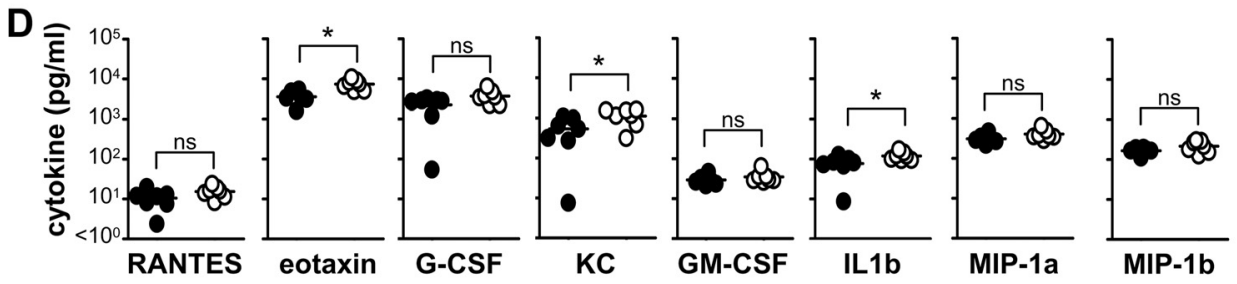
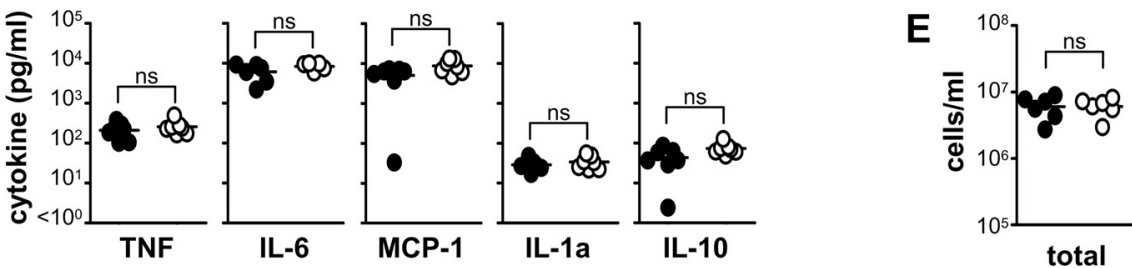

FIG. 3. C3 deficiency does not affect early inflammatory responses to C. albicans. $\mathrm{C}^{-1-}$ and wild-type mice were infected i.p. with $1 \times 10^{6} \mathrm{CFU}$ of C. albicans, and inflammatory responses were measured at $4 \mathrm{~h}$. (A) Incubation of isolated peritoneal fluid (gray histogram) or serum (unfilled histogram) with Candida albicans leads to $\mathrm{C} 3$ deposition on the fungal surface. The dark-gray portion of the histogram indicates unstained particles (secondary-only control). (B) Representative flow cytometric profiles showing the gates used (25) to identify recruited neutrophil (NØ) and monocyte/macrophage $(\mathrm{Mo})$ populations. $\mathrm{C} 3$ deficiency does not affect cellular recruitment (wild type, $5.71 \times 10^{6} \pm 4.31 \times 10^{5}$ total cells $/ \mathrm{ml}$ ) (C) or reduce inflammatory cytokine production (D) following i.p. administration of $C$. albicans. The values for the wild type are as follows: RANTES, $10.5 \pm 2.0 \mathrm{pg} / \mathrm{ml}$; G-CSF, $2,218 \pm 434 \mathrm{pg} / \mathrm{ml}$; granulocyte-macrophage CSF (GM-CSF), $29.7 \pm 3.7 \mathrm{pg} / \mathrm{ml}$; macrophage inhibitory protein $1 \alpha$ (MIP-1a), $313 \pm 36 \mathrm{pg} / \mathrm{ml}$; tumor necrosis factor (TNF), $211 \pm 37 \mathrm{pg} / \mathrm{ml}$; IL-6, 6,161 $\pm 1,169 \mathrm{pg} / \mathrm{ml}$; monocyte chemoattractant protein 1 (MCP-1), 5,062 $\pm 941 \mathrm{pg} / \mathrm{ml}$; IL-1 $\alpha$ (IL-1a), $28.8 \pm 3.6 \mathrm{pg} / \mathrm{ml} ; \mathrm{IL}-10,43.7 \pm 10.0 \mathrm{pg} / \mathrm{ml}$; and macrophage inhibitory protein $1 \beta$ (MIP-1b), $167 \pm$ $12 \mathrm{pg} / \mathrm{ml}$. Values for the wild type versus $\mathrm{C}^{-/-}$are as follows: eotaxin, $3,557 \pm 538$ versus 7,368 $\pm 811 \mathrm{pg} / \mathrm{ml} ; \mathrm{KC}, 539 \pm 142 \mathrm{versus} 1,124 \pm 180$ $\mathrm{pg} / \mathrm{ml}$; and IL-1 $\beta$ (IL-1b), $77 \pm 14$ versus $120 \pm 11 \mathrm{pg} / \mathrm{ml}$. (E) C3 deficiency also has no effect on inflammation following i.p. infections with higher doses $\left(1 \times 10^{7}\right) \mathrm{CFU}$ of $C$. albicans (wild type, $6.02 \times 10^{6} \pm 9.32 \times 10^{5}$ total cells $\left./ \mathrm{ml}\right)$. $*, P<0.05(n>6$ animals per group per experiment). The data shown in panel $\mathrm{C}$ are pooled from three independent experiments. Bars indicate mean values of the data.

Mice deficient in $\mathrm{C} 3$ are susceptible to systemic infection with $C$. glabrata. We also examined the role of $\mathrm{C} 3$ in the control of C. glabrata, another organism which has been associated with infections in immunocompromised hosts. For these experiments, wild-type and C3-deficient mice were infected i.v. with $7 \times 10^{7} \mathrm{CFU}$ and survival was monitored over time. In contrast to the wild-type mice, which were fully resistant to infection with $C$. glabrata, as expected (1), nearly all of the $\mathrm{C}^{-1-}$ mice had succumbed to infection with this organism (Fig. 6). These data therefore demonstrate that C3 is essentially required for resistance to infection with C. glabrata.

C3 deficiency protects mice against high-dose infection with S. cerevisiae. Although not normally considered a pathogen, isolates of $S$. cerevisiae have been linked to disease in immunocompromised individuals, an effect which may be related to changes in the cell wall of the organism (31). Furthermore, clinical strains of $S$. cerevisiae have been shown to cause lethal infections in C5-deficient mice (4), and we therefore explored the possibility that $\mathrm{C} 3$ would be important for resistance to infection with a nonpathogenic strain of $S$. cerevisiae. For these experiments, we infected wild-type and $\mathrm{C} 3^{-/-}$mice i.v. with a high dose $\left(1 \times 10^{8} \mathrm{CFU}\right)$ of a laboratory strain of $S$. cerevisiae and monitored survival over time (Fig. 7). Surprisingly, more than $80 \%$ of the C57BL/6 wild-type mice died within $24 \mathrm{~h}$ following i.v. administration of this organism, whereas the $\mathrm{C}^{-1-}$ animals all survived the infection. We also examined high-dose infection in DBA/2 mice, which are deficient in the C5 component of complement, and observed that these animals were also fully resistant to high-dose infection with $S$. cerevisiae (Fig. 7). However, we found that infection with this dose of $S$. cerevisiae induced only $14 \%$ mortality in wild-type $\mathrm{BALB} / \mathrm{c}$ mice, suggesting that the level of this response is dependent on the mouse strain background (Fig. 7). Overall, these results demonstrate that $\mathrm{C} 3$ can contribute to mortality upon infection with high doses of $S$. cerevisae.

\section{DISCUSSION}

Complement plays an important role in immunity to many pathogens: by direct killing through the formation of a MAC, by acting as opsonins and facilitating microbial uptake, and by inducing inflammation. Fungi, in particular, have been known 
A

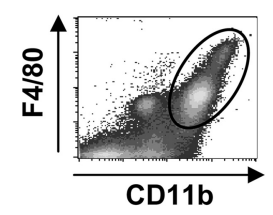

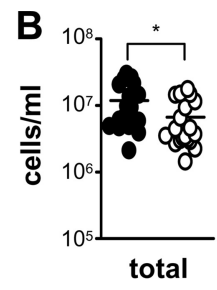

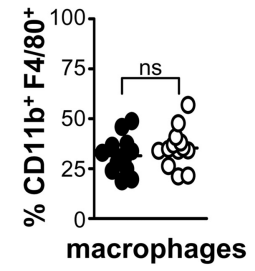

C
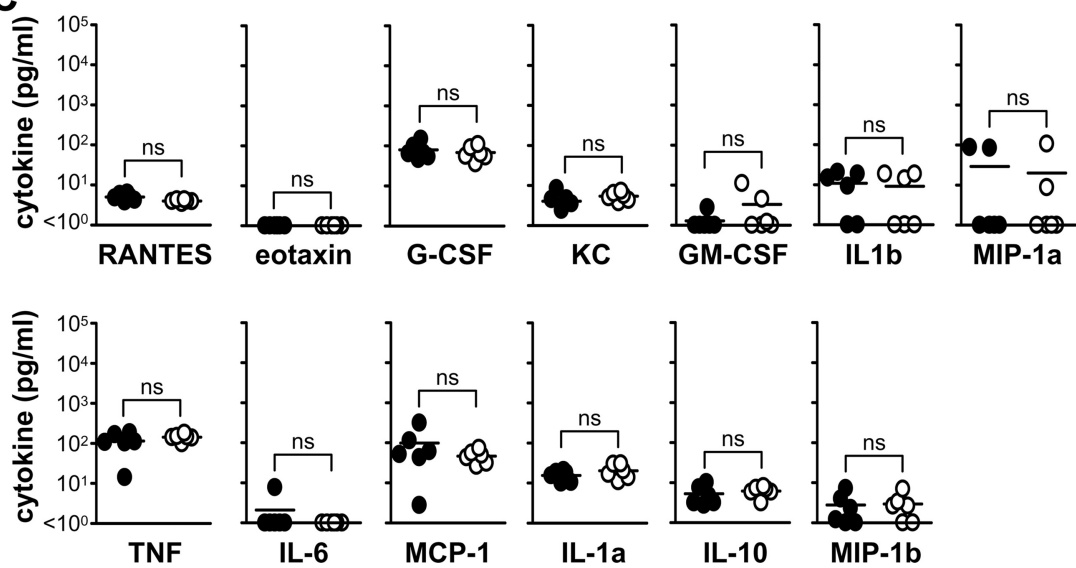

FIG. 4. C3 deficiency does not affect late inflammatory responses to C. albicans. $\mathrm{C}^{-1-}$ and wild-type mice were infected i.p. with $1 \times 10^{6} \mathrm{CFU}$ of C. albicans, and inflammatory responses were measured at day 4. (A) Representative flow cytometric profile showing the gate used (25) to identify recruited macrophages. C3 deficiency does not affect cellular recruitment (B) or inflammatory cytokine production (C) following i.p. administration of $C$. albicans. Values for the wild type versus $\mathrm{C}^{-1-}$ are as follows: $1.18 \times 10^{7} \pm 1.97 \times 10^{6}$ versus $6.65 \times 10^{6} \pm 1.20 \times 10^{6}$ total cells/ml. Values for the wild type are as follows: RANTES, $5.0 \pm 0.4 \mathrm{pg} / \mathrm{ml}$; G-CSF, $80 \pm 16 \mathrm{pg} / \mathrm{ml}$; KC, $4.1 \pm 1.1 \mathrm{pg} / \mathrm{ml}$; granulocyte-macrophage CSF (GM-CSF), $1.3 \pm 0.3 \mathrm{pg} / \mathrm{ml}$; IL-1 $(\mathrm{IL}-1 \mathrm{~b}), 10.9 \pm 3.5 \mathrm{pg} / \mathrm{ml}$; macrophage inhibitory protein $1 \alpha$ (MIP-1a), $29.5 \pm 18.0 \mathrm{pg} / \mathrm{ml}$; tumor necrosis factor (TNF), $115 \pm 25 \mathrm{pg} / \mathrm{ml}$; IL-6, $2.1 \pm 1.1 \mathrm{pg} / \mathrm{ml}$; monocyte chemoattractant protein 1 (MCP-1), $98 \pm 46 \mathrm{pg} / \mathrm{ml} ; \mathrm{IL}-1 \alpha$ (IL-1a), $15.7 \pm 1.8 \mathrm{pg} / \mathrm{ml}$; IL-10, $5.3 \pm 1.2 \mathrm{pg} / \mathrm{ml}$; and macrophage inhibitory protein $1 \beta$ (MIP-1b), $2.8 \pm 1.0 \mathrm{pg} / \mathrm{ml} . *, P<0.05(n>6$ animals per group per experiment). The data shown in panel $\mathrm{B}$ are pooled from three independent experiments. Bars indicate mean values of the data.

to trigger complement activation since the 1900s and have been used to help define the activation pathways (2). Although fungi appear to be resistant to complement-mediated killing, presumably because of their thick cell walls, the opsonic and inflammatory components of complement are thought to play a central role in antifungal immunity $(15,28)$. The role of complement has, however, largely been determined through the use of CVF, although C5-deficient mice have also been examined. Given the thrombin-dependent, C3-independent, pathway of C5 activation $(12,30)$, we undertook to examine the role of $\mathrm{C} 3$ in immunity to several opportunistic fungal pathogens using $\mathrm{C} 3$-sufficient and $\mathrm{C} 3$-deficient mice.

C. albicans can trigger all three pathways of complement activation, leading to the rapid deposition of $\mathrm{C} 3$ on the surface of this organism and facilitating its uptake by phagocytes (15). Animals treated with $\mathrm{CVF}$, or having deficiency in $\mathrm{C5}$, are more susceptible to both systemic and cutaneous candidiasis (15), and here we show that $\mathrm{C} 3$ is also an essential component of protective innate immunity to $C$. albicans. Loss of $\mathrm{C} 3$ results in increased susceptibility to infection with this organism (Fig. 1 and 2), which is due to defects in fungal clearance (Fig. 5) but not defective inflammatory responses. These results therefore suggest that that the increased inflammation seen in the kidneys and blood at 3 days (Fig. 2) is due to higher fungal burdens and not dysregulation of the inflammatory response. Indeed, although not truly representative of systemic infection, using a peritoneal model of candidiasis we could demonstrate that the inflammatory responses in C3-deficient animals were equivalent to those observed in wild-type mice (Fig. 3 and 4). Given that susceptibility due to $\mathrm{C} 5$ deficiency results from aberrant inflammatory responses (19), these results suggest that $\mathrm{C} 3$ is not essentially required for C5 activation. Under conditions of $\mathrm{C} 3$ deficiency, C5 activation is presumably mediated through the thrombin pathway $(12,30)$.

C. glabrata is another species of Candida which has been increasingly associated with opportunistic infections in immunocompromised individuals, yet relatively little is known about the host factors which mediate immunity to this organism. Unlike C. albicans, C. glabrata does not induce a lethal phenotype in immunocompetent mice, even at high inoculums (1). Although this organism can induce the alternative pathway of complement activation (5), the role of complement in the control of $C$. glabrata has not yet been examined. Here we show that mice deficient in $\mathrm{C} 3$ are highly susceptible to systemic infection with C. glabrata, demonstrating for the first time the essential role of complement in immunity to this organism.

$S$. cerevisiae is not normally considered to be a pathogen, but it has been reported to cause infections under certain settings, such as immunosuppression (15). In mice, the susceptibility of C5-deficient animals following i.v. administration with some clinical isolates has demonstrated the importance of the complement pathway in the control of infection with these micro- 

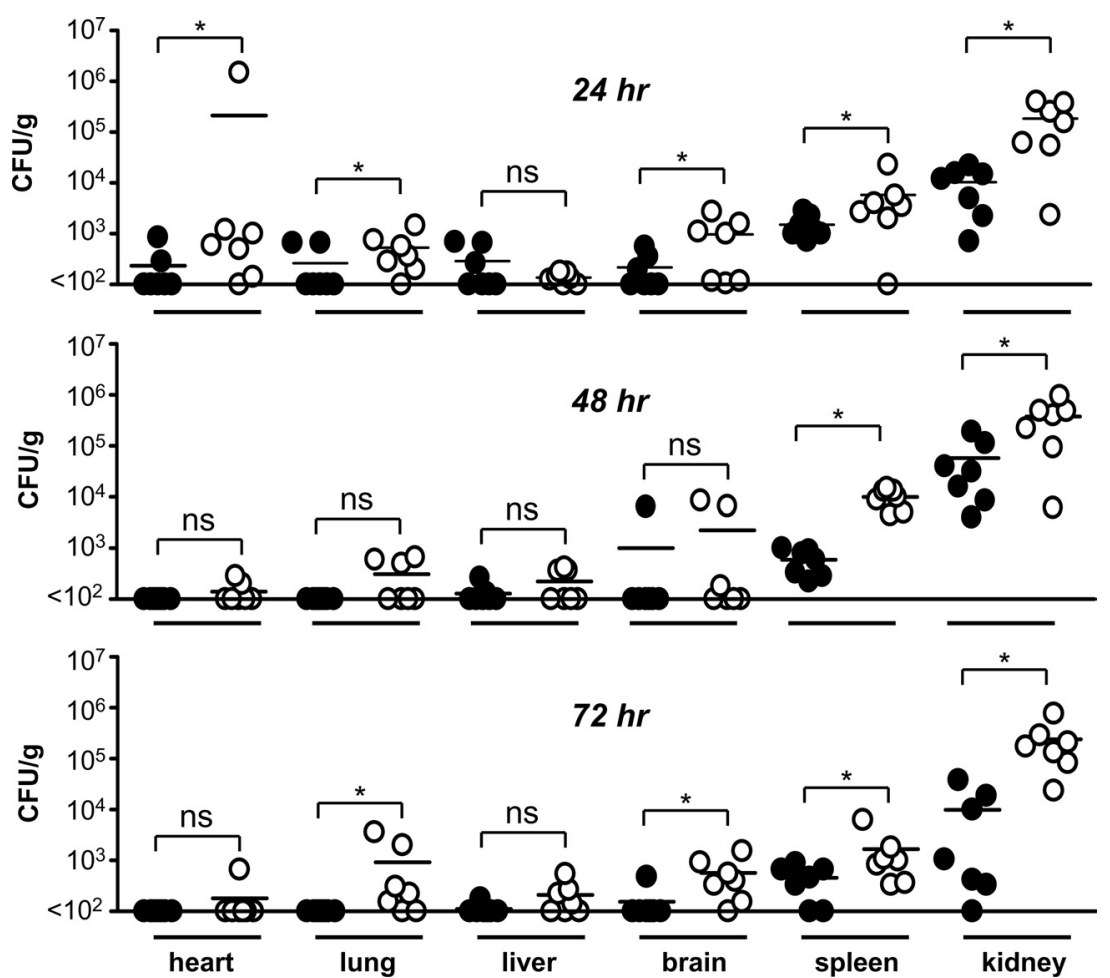

FIG. 5. C3 deficiency delays fungal clearance. $\mathrm{C}^{-/-}$and wild-type mice were infected i.v. with $1 \times 10^{4} \mathrm{CFU}$ of $C$. albicans, and fungal burdens in various organs were determined at 24,48 and $72 \mathrm{~h} . *, P<0.05(n=6$ animals per group). Bars indicate mean values of the data. Values for 24-h wild type versus $\mathrm{C}^{-1-}$ are as follows: heart, $234.6 \pm 107$ versus $212,755 \pm 212,165 \mathrm{CFU} / \mathrm{g}$; lung, $262 \pm 104$ versus $532 \pm 175 \mathrm{CFU} / \mathrm{g}$; liver, $137 \pm 12$ versus $217 \pm 68 \mathrm{CFU} / \mathrm{g}$; brain, $217 \pm 68$ versus $966 \pm 367 \mathrm{CFU} / \mathrm{g}$; spleen, $1,505 \pm 296$ versus 5,834 $\pm 2,912 \mathrm{CFU} / \mathrm{g}$; kidney, $10,350 \pm$ 2,998 versus $1.86 \times 10^{5} \pm 6.0 \times 10^{4} \mathrm{CFU} / \mathrm{g}$. Values for 48 -h wild type versus $\mathrm{C} 3^{-/-}$are as follows: heart, $<100$ versus $141 \pm 28 \mathrm{CFU} / \mathrm{g}$; lung, $<100$ versus $309 \pm 100 \mathrm{CFU} / \mathrm{g}$; liver, $128 \pm 23$ versus $222 \pm 58 \mathrm{CFU} / \mathrm{g}$; brain, $1,007 \pm 907$ versus $2,260 \pm 1,399 \mathrm{CFU} / \mathrm{g}$; spleen, $593 \pm 120$ versus $10,000 \pm$ $1,576 \mathrm{CFU} / \mathrm{g}$; kidney, $57,823 \pm 26,218$ versus $3.8 \times 10^{5} \pm 1.2 \times 10^{5} \mathrm{CFU} / \mathrm{g}$. Values for 72 -h wild type versus C3 ${ }^{-1-}$ are as follows: heart, $<100$ versus $181 \pm 81 \mathrm{CFU} / \mathrm{g}$; lung, <100 versus $926 \pm 515 \mathrm{CFU} / \mathrm{g}$; liver, $112 \pm 12$ versus $211 \pm 61 \mathrm{CFU} / \mathrm{g}$; brain, $154.3 \pm 54$ versus $572 \pm 192 \mathrm{CFU} / \mathrm{g}$; spleen, $459 \pm 113$ versus $1,672 \pm 791 \mathrm{CFU} / \mathrm{g}$; and kidney, $9,833 \pm 5,412$ versus $2.4 \times 10^{5} \pm 9.4 \pm 10^{4} \mathrm{CFU} / \mathrm{g}$.

organisms (4). Here we explored the effect of C3 deficiency upon administration of very high doses of a standard laboratory strain of $S$. cerevisiae, with the expectation that the lack of fungal clearance caused by complement deficiency may promote susceptibility, as we had observed for C. albicans. Surprisingly, we found that administration of high doses of $S$. cerevisiae caused the rapid death (within $24 \mathrm{~h}$ ) of C57BL/6

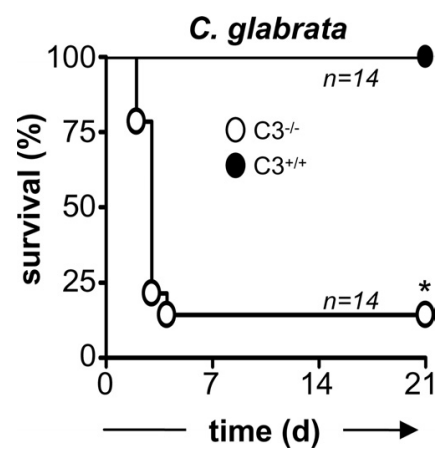

FIG. 6. C3 deficiency increases susceptibility to infection with $C$. glabrata. C57BL/6 wild-type $(\bullet)$ and C3-deficient $(\bigcirc)$ mice were infected with $7 \times 10^{7} \mathrm{CFU}$ of $C$. glabrata i.v. and were monitored for survival over 21 days, as described in Materials and Methods. The data shown are pooled from two independent experiments. *, $P<0.05$. wild-type mice and that deficiency in C3 and C5 was, in fact, protective under these conditions (Fig. 7). Inoculation of a high dose of $C$. albicans has also been shown to induce rapid lethality in mice, and in line with our findings using Saccharomyces, the loss of complement function was protective in this model (8). These results therefore suggest that complement

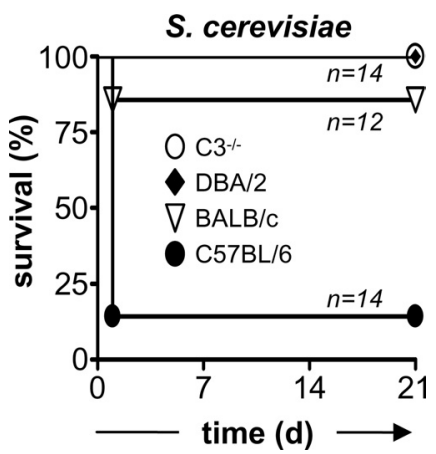

FIG. 7. C3 and C5 deficiency protects against lethality induced upon high-dose infection with $S$. cerevisiae. C57BL/6 wild-type or C3deficient, $\mathrm{DBA} / 2$, and BALB/c mice were infected with $1 \times 10^{8} \mathrm{CFU}$ of $S$. cerevisiae i.v. and were monitored for survival over 21 days, as described in Materials and Methods. The data shown are pooled from two independent experiments. *, $P<0.05$. 
itself acts in a deleterious fashion upon high dose inoculation, irrespective of the fungal species; however, the mechanisms for these effects are still unclear. Particularly intriguing is the apparent strain specificity in this response (the effect was far less marked in $\mathrm{BALB} / \mathrm{c}$ mice than in $\mathrm{C} 57 \mathrm{BL} / 6$ mice).

In conclusion, the use of gene-deficient mice has provided invaluable insights into the functions of individual components of many biological processes. We have shown here that $\mathrm{C} 3$ plays an essential role in the control of opportunistic fungal infections, but it may also contribute to mortality under certain conditions. Although our studies with $C$. albicans suggest that the primary function of $\mathrm{C} 3$ is in mediating fungal clearance, the exact role of this complement component in the control of other fungal pathogens still needs to be explored.

\section{ACKNOWLEDGMENTS}

We thank the staff of the animal facility for care of the animals used in this study and Lizette Fick for help with histology.

We thank the Wellcome Trust for funding. This work was also supported by grants from the Parker B. Francis Foundation, the American Lung Association, and NIH grant HL080317 (to C.S.). G.D.B. is a Wellcome Senior Fellow in South Africa.

\section{REFERENCES}

1. Brieland, J., D. Essig, C. Jackson, D. Frank, D. Loebenberg, F. Menzel, B. Arnold, B. DiDomenico, and R. Hare. 2001. Comparison of pathogenesis and host immune responses to Candida glabrata and Candida albicans in systemically infected immunocompetent mice. Infect. Immun. 69:5046-5055.

2. Brown, G. D., and S. Gordon. 2003. Fungal beta-glucans and mammalian immunity. Immunity 19:311-315.

3. Brown, G. D., J. Herre, D. L. Williams, J. A. Willment, A. S. J. Marshall, and S. Gordon. 2003. Dectin-1 mediates the biological effects of beta-glucan. J. Exp. Med. 197:1119-1124.

4. Byron, J. K., K. V. Clemons, J. H. McCusker, R. W. Davis, and D. A. Stevens. 1995. Pathogenicity of Saccharomyces cerevisiae in complement factor fivedeficient mice. Infect. Immun. 63:478-485.

5. Ferrante, A., and Y. H. Thong. 1979. Activation of the alternative complement pathway by Torulopsis glabrata. Scand. J. Infect. Dis. 11:77-79.

6. Fulurija, A., R. B. Ashman, and J. M. Papadimitriou. 1996. Early inflammatory responses to Candida albicans infection in inbred and complementdeficient mice. FEMS Immunol. Med. Microbiol. 14:83-94.

7. Gelfand, J. A., D. L. Hurley, A. S. Fauci, and M. M. Frank. 1978. Role of complement in host defense against experimental disseminated candidiasis. J. Infect. Dis. 138:9-16.

8. Han, Y., T. R. Kozel, M. X. Zhang, R. S. MacGill, M. C. Carroll, and J. E. Cutler. 2001. Complement is essential for protection by an IgM and an IgG3 monoclonal antibody against experimental, hematogenously disseminated candidiasis. J. Immunol. 167:1550-1557.

9. Hector, R. F., J. E. Domer, and E. W. Carrow. 1982. Immune responses to Candida albicans in genetically distinct mice. Infect. Immun. 38:1020-1028.

10. Hector, R. F., E. Yee, and M. S. Collins. 1990. Use of DBA/2N mice in models of systemic candidiasis and pulmonary and systemic aspergillosis. Infect. Immun. 58:1476-1478.

11. Held, K., S. Thiel, M. Loos, and F. Petry. 2008. Increased susceptibility of complement factor $\mathrm{B} / \mathrm{C} 2$ double knockout mice and mannan-binding lectin knockout mice to systemic infection with Candida albicans. Mol. Immunol. 45:3934-3941.

12. Huber-Lang, M., J. V. Sarma, F. S. Zetoune, D. Rittirsch, T. A. Neff, S. R McGuire, J. D. Lambris, R. L. Warner, M. A. Flierl, L. M. Hoesel, F.
Gebhard, J. G. Younger, S. M. Drouin, R. A. Wetsel, and P. A. Ward. 2006. Generation of C5a in the absence of C3: a new complement activation pathway. Nat. Med. 12:682-687.

13. Ip, W. K., and Y. L. Lau. 2004. Role of mannose-binding lectin in the innate defense against Candida albicans: enhancement of complement activation, but lack of opsonic function, in phagocytosis by human dendritic cells. J. Infect. Dis. 190:632-640.

14. Janeway, C. A., Jr. 1992. The immune system evolved to discriminate infectious nonself from noninfectious self. Immunol. Today 13:11-16.

15. Kozel, T. R. 1996. Activation of the complement system by pathogenic fungi. Clin. Microbiol. Rev. 9:34-46.

16. Kozel, T. R., L. C. Weinhold, and D. M. Lupan. 1996. Distinct characteristics of initiation of the classical and alternative complement pathways by Candida albicans. Infect. Immun. 64:3360-3368

17. Medzhitov, R. 2007. Recognition of microorganisms and activation of the immune response. Nature 449:819-826.

18. Muller-Eberhard, H. J. 1988. Molecular organization and function of the complement system. Annu. Rev. Biochem. 57:321-347.

19. Mullick, A., M. Elias, S. Picard, L. Bourget, O. Jovcevski, S. Gauthier, A. Tuite, P. Harakidas, C. Bihun, B. Massie, and P. Gros. 2004. Dysregulated inflammatory response to Candida albicans in a C5-deficient mouse strain. Infect. Immun. 72:5868-5876.

20. Netea, M. G., G. D. Brown, B. J. Kullberg, and N. A. Gow. 2008. An integrated model of the recognition of Candida albicans by the innate immune system. Nat. Rev. Microbiol. 6:67-78.

21. Netea, M. G., G. Ferwerda, C. A. van der Graaf, J. W. Van der Meer, and B. J. Kullberg. 2006. Recognition of fungal pathogens by toll-like receptors. Curr. Pharm. Des. 12:4195-4201.

22. Romani, L. 2004. Immunity to fungal infections. Nat. Rev. Immunol. 4:1-23.

23. Rosen, H., and S. Gordon. 1987. Monoclonal antibody to the murine type 3 complement receptor inhibits adhesion of myelomonocytic cells in vitro and inflammatory cell recruitment in vivo. J. Exp. Med. 166:1685-1701.

24. Speth, C., C. Lass-Florl, and R. Wurzner. 2007. Complement in fungal infections and complement evasion strategies, p. 177-199. In G. D. Brown and M. G. Netea (ed.), Immunology of fungal infections. Springer, Dordrecht, The Netherlands.

25. Taylor, P. R., G. D. Brown, A. B. Geldhof, L. Martinez-Pomares, and S. Gordon. 2003. Pattern recognition receptors and differentiation antigens define murine myeloid cell heterogeneity ex vivo. Eur. J. Immunol. 33:20902097.

26. Taylor, P. R., G. D. Brown, D. M. Reid, J. A. Willment, L. Martinez-Pomares, S. Gordon, and S. Y. C. Wong. 2002. The beta-glucan receptor, Dectin-1, is predominantly expressed on the surface of cells of the monocyte/macrophage and neutrophil lineages. J. Immunol. 269:3876-3882.

27. Taylor, P. R., S. V. Tsoni, J. A. Willment, K. M. Dennehy, M. Rosas, H. Findon, K. Haynes, C. Steele, M. Botto, S. Gordon, and G. D. Brown. 2007. Dectin-1 is required for beta-glucan recognition and control of fungal infection. Nat. Immunol. 8:31-38.

28. Triebel, T., B. Grillhosl, L. Kacani, C. P. Lell, A. Fuchs, C. Speth, C. Lass-Florl, J. Steinmann, M. P. Dierich, and R. Wurzner. 2003. Importance of the terminal complement components for immune defence against Candida. Int. J. Med. Microbiol. 292:527-536.

29. Wessels, M. R., P. Butko, M. Ma, H. B. Warren, A. L. Lage, and M. C. Carroll. 1995. Studies of group B streptococcal infection in mice deficient in complement component $\mathrm{C} 3$ or $\mathrm{C} 4$ demonstrate an essential role for complement in both innate and acquired immunity. Proc. Natl. Acad. Sci. USA 92:11490-11494.

30. Wetsel, R. A., and W. P. Kolb. 1983. Expression of C5a-like biological activities by the fifth component of human complement (C5) upon limited digestion with noncomplement enzymes without release of polypeptide fragments. J. Exp. Med. 157:2029-2048.

31. Wheeler, R. T., M. Kupiec, P. Magnelli, C. Abeijon, and G. R. Fink. 2003. A Saccharomyces cerevisiae mutant with increased virulence. Proc. Natl. Acad. Sci. USA 100:2766-2770.

32. Willment, J. A., and G. D. Brown. 2008. C-type lectin receptors in antifungal immunity. Trends Microbiol. 16:27-32. 